\title{
Enhancement of Oral Bioavailability of
} Ibandronate Through Gastroretentive Raft Forming Drug Delivery System: In Vitro and In Vivo Evaluation

\author{
This article was published in the following Dove Press journal: \\ International Journal of Nanomedicine
}

\author{
Muhammad Hanif' \\ Shahid Shah (iD ${ }^{2}$ \\ Akhtar Rasul $^{3}$ \\ Ghulam Abbas $\mathbb{D}^{3}$ \\ Muhammad Zaman (iD ${ }^{4}$ \\ Muhammad Wahab Amjad ${ }^{5}$ \\ Maria Abdul Ghafoor Raja ${ }^{5}$ \\ Hafeez Ullah Khan ${ }^{6}$ \\ Mehran Ashfaq ${ }^{3}$ \\ Omeira $|q b a|^{3}$
}

'Department of Pharmaceutics, Faculty of Pharmacy, Bahauddin Zakariya University, Multan, Pakistan; ${ }^{2}$ Department of

Pharmacy Practice, Faculty of Pharmaceutical Sciences, Government College University, Faisalabad, Pakistan;

${ }^{3}$ Department of Pharmaceutics, Faculty of Pharmaceutical Sciences, Government College University, Faisalabad, Pakistan; ${ }^{4}$ Faculty of Pharmacy, University of Central Punjab, Lahore, Pakistan;

${ }^{5}$ Department of Pharmaceutics, Faculty of Pharmacy, Northern Border University,

Rafha, Saudi Arabia; ${ }^{6}$ College of

Pharmacy, University of Sargodha,

Sargodha, Pakistan
Correspondence: Ghulam Abbas Department of Pharmaceutics, Faculty of Pharmaceutical Sciences, Government College University, Faisalabad, Pakistan Email ghulamabbas@gcuf.edu.pk
Background: Bisphosphonates have very low bioavailability and cause irritation of the esophagus and stomach. This study was planned to improve the oral bioavailability of ibandronate through the formation of a raft in the stomach. Bisphosphonate-induced irritation of the esophagus and stomach is prevented by the formation of a raft.

Materials and Methods: The nanostructured raft was developed through the use of nanosized citrus pectin (NCP). The particle size of NCP was measured by zeta sizer and SEM. The percentage of NCP and the neutralization profile of raft was studied. The ibandronate, polymers, and the developed formulation were characterized by FTIR, XRD, TGA, and DSC. The release of ibandronate was studied in $0.1 \mathrm{~N} \mathrm{HCl}, 0.5 \mathrm{~N} \mathrm{HCl}, 1 \mathrm{~N} \mathrm{HCl}$, and simulated gastric fluid (SGF) and a cell viability study was performed using Caco-2 cells. The PPR5 formulation and Bonish $150 \mathrm{mg}$ tablets were selected as test and reference formulations, respectively, for pharmacokinetic study. Twelve healthy albino rats were taken and divided into two groups using a Latin square crossover design, and the blood samples were collected for 24 hours.

Results: The SEM image showed that the particle size of NCP was $159 \mathrm{~nm}$. The raft of PPR5 showed 94\% NCP and 45 minutes duration of neutralization. The FTIR and XRD showed chemical stability and a uniform distribution of ibandronate in the raft. The TGA and DSC indicated the thermal stability of formulation. The release of $99.87 \%$ ibandronate at 20 minutes was observed in the SGF. The values of $C_{\max }$ for the reference and test formulations were $493 \pm 0.237 \mathrm{ng} / \mathrm{mL}$ and $653 \pm 0.097 \mathrm{ng} / \mathrm{mL}$, respectively. The $\mathrm{AUC}_{(0-\mathrm{t})}$ of the reference and test formulations was $3708.25 \pm 3.418 \mathrm{ng} / \mathrm{mL}$.h and $6899.25 \pm 3.467 \mathrm{ng} / \mathrm{mL} . \mathrm{h}$, respectively. Conclusion: The NCP has been successfully prepared from citrus pectin and has shown effective porous raft formation. The bioavailability of the ibandronate from newly developed PPR5 was higher than the already marketed formulation.

Keywords: nanosized citrus pectin, raft, in vitro release, cell viability, pharmacokinetics

\section{Introduction}

Bisphosphonates are used in the management of a variety of diseases related to Paget's disease, malignancy induced hypercalcemia, post-menopausal osteoporosis, and bone resorption. For drugs belonging to BCS class III (high solubility and low permeability), achieving the desired bioavailability is quite difficult due to the low permeability of the drug through gastrointestinal mucosa. Ibandronate, a famous 
bisphosphonate belonging to the BCS class III used in therapy for the treatment of osteoporosis, has very low bioavailability when administered orally in the form of conventional tablets. ${ }^{1}$ Oral bisphosphonate therapy, including ibandronate linked to upper gastrointestinal injury, has unfortunately raised concerns. Reports of adverse experiences have shown that oral bisphosphonate can potentially cause severe intolerance to the upper gastrointestinal tract due to irritation of the local mucosa, particularly to produce unwanted esophageal experiences, such as esophagitis, ulcers, and erosions in a small percentage of patients.

In recent decades, polymers have been extensively used as raw constituents for proposed drug delivery systems due to their excellent properties, such as non-toxicity, biocompatibility, biodegradability, and environmental sensitivity, etc. Pectin is one of the most abundant natural biopolymers, which is isolated and purified from citrus peel. $^{2}$ This polymer is insoluble in water and has good film-forming properties. Pectin has gained many attractions in the pharmaceutical and medical applications. Due to its exclusive antacid and antiulcer features as well as its gelling and film forming properties, pectin has a great prospective for use as a suitable carrier in drug delivery systems. The pectin is processed in the laboratory by an appropriate method to convert it to NCP, which is then used in the study for the formation of the effective porous nature of the raft.

The raft forming delivery system is formulated containing NCP as the raft former, sodium bicarbonate as effervescent mixture, calcium carbonate to enhance the raft strength, and polyethylene glycol (PEG 400) as the permeability enhancer, while it is necessary to mention that the absorption window of ibandronate is located inside the stomach and the raft forming system ensures the availability of drug at gastric mucosa for a relatively prolonged time period. The addition of the permeability enhancer and prolonging the residence time of the delivery system at its absorption window increased the bioavailability of ibandronate. The purpose of this research work was to enhance the oral bioavailability of ibandronate through a raft forming delivery system. The NCP and PEG 400 were used as raft former and penetration enhancer, respectively. The developed raft was evaluated by FTIR, XRD, TGA, DSC, and cell viability study. The pharmacokinetic of ibandronate was studied on albino rats.

\section{Materials and Methods \\ Chemicals and Reagents}

Ibandronate was gifted by Global Pharmaceuticals Pvt. Ltd. Islamabad, Pakistan. citrus pectin, PEG 400, crosslinked carboxymethyl cellulose (CCMC), potassium dihydrogen phosphate, acetonitrile, sodium chloride and ethanol were purchased from Sigma-Aldrich Gmbh, Germany. Calcium carbonate, citric acid, sodium bicarbonate and pectin esterase (PE) were obtained from Merck Darmstadt, Germany. Bonish (150 mg tablets) was purchased from a local market.

\section{Preparation of Nanosized Citrus Pectin (NCP)}

The NCP was prepared by the method already reported by Jiang et $\mathrm{al}^{3}{ }^{3}$ in 2001 . Only a $1 \%$ solution of citrus pectin was prepared using $0.4 \mathrm{M} \mathrm{NaCl}$ solution and adjusted the $\mathrm{pH}$ to 6.5 by $0.1 \mathrm{~N} \mathrm{NaOH}$ solution. Then $6 \mathrm{~mL}$ of citrus pectin solution was mixed with an equal volume of $0.2 \mathrm{M}$ phosphate buffer $\mathrm{pH} 6.5$ and centrifuged at 15,000 rpm for 10 minutes. The supernatant was obtained and filtered through a $0.45 \mu \mathrm{m}$ filter. The obtained citrus pectin solution was mixed with 100 units $/ \mathrm{mL}$ of pectin esterase (PE). The PE-citrus pectin solution was incubated at $30^{\circ} \mathrm{C}$ for 16 hours and the solution was placed in a water bath to stop the reaction for 3 minutes. The solution was dried in an oven at $45^{\circ} \mathrm{C}$ for 4 hours. The particle size of the dried NCP was determined by a particle size analyzer and SEM.

\section{Preparation of Raft Forming Tablets}

The tablets for prompt delivery of ibandronate were prepared by wet granulation method. ${ }^{4}$ The ibandronate, NCP, PEG 400, and other excipients were mixed thoroughly, as shown in Table 1. The powdered mixture of ibandronate and other excipients was mixed using a Sigma mixer. The powdered mixture was granulated using $2 \%(\mathrm{w} / \mathrm{w})$ HPMC E5 in a $90 \%$ solution of ethanol. The granules were dried at $40^{\circ} \mathrm{C}$ for 2 hours, passed through 18-mesh screen and compressed using a minipress MII (Pharma Test, Hainburg, Germany).

\section{Disintegration Time of Tablets}

One tablet was placed in a $250 \mathrm{~mL}$ beaker containing $120 \mathrm{~mL}$ of water at room temperature to measure the disintegration time. The tablet was disintegrated if the evolution of gas around the tablet or its fragments stopped, being either dissolved or dispersed in water so that no agglomerate remains. The process was repeated on four further tablets. 
Table I Composition of NCP Raft Forming Formulations

\begin{tabular}{|l|l|l|l|l|l|l|l|}
\hline Code & Ibandronate (\%) & NCP (\%) & CCMC (\%) & PEG 400 (\%) & NaHCO $_{\mathbf{3}}$ (\%) & Citric acid (\%) & CaCO \\
(\%) \\
\hline PPRI & 30.00 & 12.50 & 2.00 & 2.00 & 28.00 & 14.00 & 11.50 \\
PPR2 & 30.00 & 27.50 & 2.00 & 2.00 & 19.00 & 9.50 & 10.00 \\
PPR3 & 30.00 & 10.00 & 2.00 & 2.00 & 30.00 & 15.00 & 11.00 \\
PPR4 & 30.00 & 12.50 & 2.00 & 2.00 & 30.00 & 15.00 & 8.50 \\
PPR5 & 30.00 & 10.00 & 2.00 & 2.00 & 32.00 & 16.00 & 8.00 \\
PPR6 & 30.00 & 2.50 & 2.00 & 2.00 & 36.00 & 18.00 & 9.50 \\
PPR7 & 30.00 & 2.50 & 2.00 & 2.00 & 39.00 & 19.50 & 18.50 \\
PPR8 & 30.00 & 7.50 & 2.00 & 2.00 & 37.00 & 3.00 & 3.00 \\
PPR9 & 30.00 & 5.00 & 2.00 & 2.00 & 39.00 & 19.50 & 2.50 \\
\hline
\end{tabular}

\section{Hardness of Tablets}

This was measured because, during preparation, transportation, and storage of tablets, the dosage forms faces the mechanical shock. Much equipment is available for the measurement of hardness of tablets. The hardness of tablets was measured in $\mathrm{Kg} / \mathrm{cm}^{2}$ by using Erweka hardness tester (Gmbh Germany).

\section{Properties of NCP Raft Determination of NCP in the Raft}

The percentage of NCP in the raft was determined by the previously established HPLC method. Then $150 \mathrm{~mL}$ of SGF was placed in a beaker and the temperature was maintained at $37^{\circ} \mathrm{C}$. The tablet was put in a beaker and we waited until the raft was completely formed. The raft was transferred to the Büchner funnel using a spatula, and washed with purified water $(n=3)$. The raft was transferred to a centrifuge tube with the help of a spatula and a sufficient amount of purified water was added. Ethanol was added at $4^{\circ} \mathrm{C}$ to a centrifuge tube and centrifuged for 5 minutes at $5000 \mathrm{rpm}$. The raft was placed in an oven at $40^{\circ} \mathrm{C}$ after removing it from the centrifuge tube. The fine powder of the raft was made by grinding, placed in a centrifuge tube, $5 \mathrm{~mL}$ of phosphate buffer at $\mathrm{pH} 7.4$ was added and centrifuged for 5 minutes at $5000 \mathrm{rpm}$. The upper clear layer was removed, filtered through $0.22 \mu \mathrm{m}$ filter, and injected into an HPLC system for analysis. The following equation was used to calculate the contents of the NCP.

$$
\begin{aligned}
\text { Contents of } \mathrm{NCP}= & (\mathrm{Xmg} / \mathrm{mL}) \\
& \times \frac{\mathrm{V}(\mathrm{mL}) \times \text { total raft weight }(\mathrm{mg})}{\text { weight of sample }(\mathrm{mg})}
\end{aligned}
$$

\section{Acid Neutralization Capacity (ANC) Within the Raft}

The acid neutralization capacity of the raft was measured to understand the ability of the raft to retain the antacid and to provide an antacid reservoir with a benefit. The two flasks were taken with a capacity of $500 \mathrm{~mL}$. De-ionized water and $1 \mathrm{M} \mathrm{HCl}$ was added to flask one and it was incubated at $37^{\circ} \mathrm{C}$ for 20 minutes using a water bath, which was reagent $\mathrm{A} ; 0.5 \mathrm{M} \mathrm{NaOH}$ was added to the second flask and heated for 20 minutes at $37^{\circ} \mathrm{C}$, which was reagent B. The tablet was placed in a beaker and left until the raft was completely formed. The raft was transferred to a centrifuge tube after washing with purified water $(n=3)$. A sufficient amount of purified water was added, with ethanol at $4^{\circ} \mathrm{C}$, and it was centrifuged for 5 minutes at $5000 \mathrm{rpm}$. The raft was placed in an oven at $40^{\circ} \mathrm{C}$ after removing it from the centrifuge tube. Powder of the raft was placed in a conical flask with $150 \mathrm{~mL}$ of purified water. $^{5}$ The flask was placed over a shaker at $250 \mathrm{rpm}$ for 60 seconds with $30 \mathrm{~mL}$ of reagent $\mathrm{A}$. With a burette, reagent $\mathrm{B}$ was added and the titration analysis started. The $\mathrm{pH}$ meter was used to check the changes in $\mathrm{pH}$. The following equation was used to calculate the ANC.

$$
\mathrm{ANC}=\mathrm{V}-\mathrm{T} \times 0.5 \times \frac{\text { total mass of } \mathrm{raft}(\mathrm{mg})}{\text { wieght of sample }(\mathrm{mg})}
$$

where $\mathrm{V}$ is the volume $(\mathrm{mL})$ of $\mathrm{HCl}$, and $\mathrm{T}$ is the volume $(\mathrm{mL})$ of titre.

\section{Profile of Neutralization}

The neutralization profile of the raft is used to measure the capacity for the raft to act as a reservoir of antacids and provide sustained protection against gastric acid of stomach; $150 \mathrm{~mL}$ of SGF were taken in a beaker and the temperature was maintained at $37^{\circ} \mathrm{C}$. The tablet was placed in a beaker 
and left until the raft was completely formed. The developed NCP raft was transferred to a Büchner funnel and any media were discarded. It was left for 5 minutes and then $3 \mathrm{~mL}$ of $0.04 \mathrm{M} \mathrm{HCl}$ was added on the raft. The obtained solution was discarded and $0.1 \mathrm{M} \mathrm{HCl}$ solution was placed on the raft for filtration $(\mathrm{n}=3)$, the solution was collected, and $\mathrm{pH}$ was recorded by $\mathrm{pH}$ meter (digital). ${ }^{5}$

\section{Swelling of NCP Raft}

Then $150 \mathrm{~mL}$ of SGF were taken in a beaker and the temperature was maintained at $37^{\circ} \mathrm{C}$. The tablet was placed in a beaker and left until the raft was completely formed. The raft was transferred to the Büchner funnel using a spatula, and left until the supernatant was completely removed. The raft was transferred to the electronic weight balance with the help of a spatula and weighed $\left(W_{0}\right)$. A plastic container was taken having a solution of 0.1 $\mathrm{N} \mathrm{HCl}$, the raft was added in it with a mesh and placed on a shaker (orbit). The raft was removed from the plastic container after 10, 20, 30, 40, 50, and 60 minutes, the extra water was removed, and it was weighed $\left(W_{1}\right)$. The raft was placed in an over oven at $80^{\circ} \mathrm{C}$ and dried until constant weight and the final weight was recorded $\left(W_{2}\right){ }^{6}$ The swelling was calculated using the following equation.

$$
\% \text { Swelling of pectin raft }=\frac{W_{1}-W_{2}}{W_{0}} \times 100
$$

\section{Floating Lag Time (FLT) Total Floating Time (TFT)}

FLT and TFT of the NCP raft were determined by using USP dissolution apparatus II (pharma test Hainburg, Germany) using $900 \mathrm{~mL}$ SGF pH 1.2 maintained at $37 \pm 0.5^{\circ} \mathrm{C}$ and at $50 \mathrm{rpm}$. The time required for the raft to rise to the surface and float was determined as FLT. TFT is the total time for which the raft floats in dissolution medium including FLT.

\section{Characterization}

The XRD diffractograms, FTIR spectra, TGA, and DSC thermograms of ibandronate, NCP, CCMC, and the raft of PPR5 were obtained using a diffractometer, FTIRspectrophotometer (Bruker Alpha, Germany), TGA analyzer, and differential scanning-calorimeter DSC-60 (Shimadzu, Germany) respectively. The FTIR spectra was recorded in the wavelength range of 4000 to $1000 \mathrm{~cm}^{-1}$. The samples for TGA and DSC was placed in an aluminium pan and analyzed under a $100 \mathrm{~mL} / \mathrm{min}$ gas stream of nitrogen and heating rate was 50 to $400^{\circ} \mathrm{C}$.

\section{Ibandronate Release from Nanostructured Raft}

The release of ibandronate from raft forming tablets was determined by a method already reported by Jang et $\mathrm{al}^{7}$ in 2014. The tablet was placed in $50 \mathrm{~mL}$ of four different acidic mediums, ie, SGF, $0.1,0.5$, and $1.0 \mathrm{~N} \mathrm{HCl}$ solution in $250 \mathrm{~mL}$ capacity beaker. The temperature was maintained at $37^{\circ} \mathrm{C}$ and $2 \mathrm{~mL}$ of sample was collected at 5,10 , $15,20,25,30,45$, and 60 minutes. The same volume of fresh dissolution medium was added into the beaker containing tablets for dissolution study to maintain the sink condition. The samples obtained at regular time intervals were filtered through a $0.22 \mu \mathrm{m}$ filter and injected into the HPLC system for analysis. The concentration of ibandronate in tablets was analyzed using a HPLC system with UV detection (PerkinElmer, Shelton, CT, ) with RHS $\mathrm{C}_{18}$ column $(1.5 \mathrm{~cm} \times 4.6 \mathrm{~mm}, 5 \mu \mathrm{m})$ (Agilent technologies, Santa Clara, CA). The analysis was performed using a mobile phase consisting of acetonitrile and $0.01 \mathrm{M}$ sodium dihydrogen phosphate in a ratio of $20: 80 \% \mathrm{v} / \mathrm{v}$ at a flow rate of $1 \mathrm{~mL} / \mathrm{min}$. The $\mathrm{pH}$ of the mobile phase was adjusted to 3.3 using $10 \%$ ortho-phosphoric acid. The detection wavelength was set at $195 \mathrm{~nm}$. The retention time of ibandronate was $4.598 \pm 0.1$ minutes. The linearity parameter was studied in the range of 200 to $800 \mathrm{ng} / \mathrm{mL}$ with a correlation coefficient $\left(R^{2}\right)$ of 0.999 . Percentage recovery was calculated as $100.7 \%$. The percentage relative standard deviation of precision value was found to be less than $2 \%$.

\section{Cell Viability Study (Commercially Purchased Cells)}

Cell viability was done by MTT assay using the Caco-2 model to evaluate the cellular toxicity of the NCP raft. The Caco-2 cell line was purchased commercially (American Type Culture Collection, ATCC, Manassas, VA). Briefly, the Caco-2 cells were seeded in 96-well plates in Eagle's Minimum Essential Medium (Catalog No. 30-2003) with $20 \%$ fetal bovine serum (FBS). After confluence, the cells were incubated with DMEM without FBS and having $0.5 \%$ dispersions of various samples for 6 and 24 hours. After incubation, the samples were removed thoroughly and washed three times with phosphate buffered saline (1X PBS). Then, $500 \mu \mathrm{L}$ MTT solutions in FBS-free medium $(0.5 \mathrm{mg} / \mathrm{mL})$ were added to each well and the cells were incubated for 1 hour. After removal of the supernatants, the converted dye was solubilized with $500 \mu \mathrm{L}$ of DMSO. The absorbance of the resulting solution was recorded 
immediately at $\lambda=570 \mathrm{~nm}$. The percentage of cell viability was calculated using the following equation;

$$
\text { Cell viability }(\%)=\frac{\mathrm{As}}{\mathrm{Ad}} \times 100
$$

As and Ad are the absorbance measured after treatment with sample dispersions and DMEM, respectively.

\section{Stability Studies}

The stability studies were carried out according to $\mathrm{ICH}$ guidelines for 6 months by storing the PPR5 formulation in a stability chamber at $40^{\circ} \mathrm{C}$ and $75 \pm 5 \%$ relative humidity. ${ }^{8}$ The samples of optimized formulation were evaluated for disintegration time, hardness of tablets, FLT, TFT, \% drug content, and \% release profile of ibandronate after 1,3 , and 6 months.

\section{Pharmacokinetic Analysis}

With the approval of the Ethical Committee for Utilization of Laboratory Animals, Government College University Faisalabad, Pakistan, healthy albino rats weighing 400-600 $\mathrm{g}$ were divided into two groups (control and test group) having six rats in each. The ICH guidelines were followed for the handling and welfare of animals during the pharmacokinetic study. The animals were raised under normal conditions with free access to standard diet and water, housed in a well maintained room at $25 \pm 5^{\circ} \mathrm{C}$ with a $12: 12$ hour lightdark cycle. Animals were fasted for 24 hours before starting the experiment but allowed free access to water. A single dose of Bonish $150 \mathrm{mg}$ tablets (equivalent to $1 \mathrm{mg} / \mathrm{kg}$, control group) and the PPR5 (equivalent to $1 \mathrm{mg} \mathrm{drug} / \mathrm{kg}$, test group) was administered orally through a feeding tube followed by rinsing with water. All animals were tagged properly and retained in the wooden boxes during the sampling procedure. At pre-dose $(\mathrm{t}=0)$, and at $0.5,1,2,3,4,6,8,12$, and 24 hours after administration, a $0.25 \mathrm{~mL}$ blood sample was collected from the tail vein of the rat into heparinised micro-centrifuge tubes. Plasma samples were prepared by centrifugation of the blood $(5500 \times \mathrm{g}$ for 10 minutes), aspiration into cryo-vials and stored at $-20{ }^{\circ} \mathrm{C}$. A liquid-liquid extraction was performed to obtain ibandronate from plasma samples. To $100 \mu \mathrm{L}$ aliquot of plasma, $100 \mu \mathrm{L}$ of acetonitrile was added, vortexed for 20 minutes and centrifuged (Hermile $\mathrm{Z} 220-\mathrm{A}$ ) at $4000 \mathrm{rpm}$ for 25 minutes. After centrifugation, an organic layer was withdrawn by using a micropipette and solvent was dried under a gentle stream of nitrogen at $45^{\circ} \mathrm{C}$. The residue was reconstituted with $100 \mu \mathrm{L}$ of the mobile phase and analysed by high performance liquid chromatography-UV spectrometry.

\section{Data Analysis}

The concentrations of ibandronate in plasma samples were calculated based on the calibration curve over the range of $200-800 \mathrm{ng} / \mathrm{mL}$ using Microsoft ${ }^{\circledR}$ Office Excel 2010. Pharmacokinetic parameters were estimated by using scientific application package Kinetica $R$ version 4.1.1 (Thermo Electron Coorporation, USA). Values for maximum plasma concentration $\left(\mathrm{C}_{\max }, \mathrm{ng} / \mathrm{mL}\right)$ and time to reach the peak plasma concentration $\left(\mathrm{t}_{\max }, \mathrm{h}\right)$ were determined directly from the average obtained data using Equations (5) and (6). Area under the plasma concentration time curve to time $\mathrm{t}\left(\mathrm{AUC}_{0-\mathrm{t}}, \mathrm{ng} / \mathrm{mL} . \mathrm{h}\right)$ and area under the plasma concentration time curve to infinity $\left(\mathrm{AUC}_{0-\infty}, \mathrm{ng} / \mathrm{mL} . \mathrm{h}\right)$ were calculated by mixed loglinear method using Equation (7). AUMC was calculated using Equation (8). Elimination half-life $\left(\mathrm{kel}, \mathrm{h}^{-1}\right)$, Clearance $\left(\mathrm{Cl}, \mathrm{h}^{-1}\right)$, and mean residence time (MRT, h) were calculated using Equation (9).

$$
\begin{gathered}
C_{\max }=\frac{\mathrm{FX}_{0}}{\mathrm{~V}_{\mathrm{d}}} \times \mathrm{e}^{-\mathrm{kt}_{\max }} \\
t_{\max }=2.303 \log \left(\mathrm{K}_{\mathrm{a}} / \mathrm{K}_{\mathrm{e}}\right)\left(\mathrm{K}_{\mathrm{a}}-\mathrm{K}_{\mathrm{e}}\right) \\
\mathrm{AUC}_{0-\mathrm{t}}=\sum_{1}^{\mathrm{n}} \frac{\mathrm{C}_{\mathrm{i}}+\mathrm{C}_{\mathrm{i}}+1}{2} \cdot \Delta \mathrm{t} \\
\mathrm{AUMC}_{0-\mathrm{t}}=\sum_{1}^{\mathrm{n}} \frac{\mathrm{t}_{\mathrm{i}}\left(\mathrm{C}_{\mathrm{i}}+\mathrm{C}_{\mathrm{i}}+1\right)}{2} \cdot \Delta \mathrm{t} \\
\mathrm{MRT}=\frac{\mathrm{AUMC}}{\mathrm{AUC}}
\end{gathered}
$$

where $\mathrm{F}, \mathrm{Vd}$, and $\mathrm{k}$ are administered dose fraction, volume of distribution, and rate constant, respectively. $\mathrm{K}_{\mathrm{a}}$ and $\mathrm{K}_{\mathrm{e}}$ are rate constants for absorption and elimination, respectively. $\Delta t\left(t_{2}-t_{1}\right), C_{i}$, and $C_{i+1}$ are time interval, initial amount, and final amount of the drug, respectively.

\section{Statistical Analysis}

The pharmacokinetic data was statistically analyzed using SPSS version 17 (SPSS Inc., Chicago, IL). The software program SPSS (SPSS 17) Student's $t$-test was performed to compare the parameters between the control group and test group, with confidence interval at $95 \%$. 


\section{Results and Discussion}

\section{Disintegration and Hardness of Tablets}

The disintegration time of nine formulations ranged from $23 \pm 0.02-56 \pm 0.02$ seconds, as shown in Table 2. Hanif and Abbas $^{9,10}$ and Abbas et alobserved a similar pattern of disintegration time of raft forming tablets containing sodium alginate and pectin. Formulations containing less amount of pectin showed a decrease in disintegration time as compared to the formulations having a high amount of pectin. Higher concentrations of sodium bicarbonate containing formulation rapidly disintegrate as compared to the formulations having a lower amount of sodium bicarbonate. ${ }^{11}$ The tablet hardness was found between $4.05 \pm 0.20-4.92 \pm 0.12 \mathrm{~kg} / \mathrm{cm}^{2}$, as shown in Table 2. Akseli et $\mathrm{al}^{12}$ studied a similar pattern of hardness of tablet formulations using pre- and postcompressional force analysis.

\section{Particle Size Analysis}

The particle size of the NCP ranged from $50-500 \mathrm{~nm}$, as mentioned in Figure 1A; 50\% of the particles are sized $60-90$ $\mathrm{nm}$. The lower percentage of the particles fell in the range of more than $100 \mathrm{~nm}^{13}$ The SEM images of NCP showed particle size in the nano range. ${ }^{14}$ The image of SEM showed that the size of the particle was $159 \mathrm{~nm}$, as shown in Figure 1B.

\section{Chemical Properties of Raft}

The integrity and strength of the raft depends upon the percentage of NCP in the raft. Antacids are also trapped in the polymeric gel to extend the neutralization time. ${ }^{10}$ The antacids in the formulation immediately neutralize the acid in the stomach and reduce the burning sensation. A raft was effectively formed on the surface of the SGF when adding tablets of formulations PPR1 to PPR5, but a raft did not develop when adding formulations PPR6 to PPR9.

Table 2 Results of Disintegration and Hardness of Tablets

\begin{tabular}{|l|l|l|}
\hline Code & Disintegration Time (Seconds) & Hardness $\left(\mathbf{k g} / \mathbf{c m}^{2}\right)$ \\
\hline PPRI & $54 \pm 0.06$ & $4.92 \pm 0.12$ \\
PPR2 & $53 \pm 0.02$ & $4.81 \pm 0.19$ \\
PPR3 & $50 \pm 0.03$ & $4.84 \pm 0.14$ \\
PPR4 & $56 \pm 0.02$ & $4.89 \pm 0.41$ \\
PPR5 & $49 \pm 0.06$ & $4.90 \pm 0.12$ \\
PPR6 & $26 \pm 0.04$ & $4.18 \pm 0.55$ \\
PPR7 & $23 \pm 0.02$ & $4.17 \pm 0.19$ \\
PPR8 & $25 \pm 0.01$ & $4.13 \pm 0.11$ \\
PPR9 & $24 \pm 0.03$ & $4.05 \pm 0.20$ \\
\hline
\end{tabular}

The PPR 1 formulation contains $85 \% \mathrm{NCP}$, the PPR 2 formulation contains $78 \%$ NCP, the PPR3 formulation contains $62 \% \mathrm{NCP}$, as shown in Figure 2A, and the PPR4 formulation contained $61 \% \mathrm{NCP}$ and the PPR5 formulation contained $94 \%$ NCP. The higher concentration of NCP was observed in the PPR5 formulation due to a better crosslinking pattern of raft through calcium ions. ${ }^{15}$ The higher concentration of NCP in the raft increases the strength and integrity and effectively stops the reflux of gastric acid from the stomach to esophagus. The calcium ions promote the crosslinking pattern of the nano-structured raft. The raft forming formulations have an initial acid ANC based on their contents of antacid, some of it is utilized to neutralize the acid pocket as soon as the formulation is ingested, however there is a significant residual amount that ends up trapped within the nano-structured raft, as was observed during the process of raft formation. The ANC of the raft was measured to recognize the capacity of the raft to preserve the antacid and deliver a pool of antacids. The raft of the PPR5 formulation showed the highest ANC value (7.0), which was significantly ( $P$-value is less than 0.05 ) different from the other formulations, as shown in Figure 2B. The ANC of the PPR1 formulation was $6.8(P$-value is less than 0.05), which was less than the PPR5 formulation but greater than that of the PPR2, PPR3, and PPR4 formulations, which were $3.2,3.0$, and 2.7 , respectively. The high ANC of the PPR5 formulation was observed due to the higher concentration of antacids as compared to the other formulations. ${ }^{5}$ Previous studies suggested that antacids are trapped inside the raft, but this has not been measured. A method has been developed to measure the ANC of the raft. Antacids inside the raft will cause initial but often transient neutralization of the acid. An effective formulation for raft formation must have a high ANC and a long neutralization duration. The neutralization profile was used to verify the ability of the raft to neutralize the acid that passes through it. The duration of neutralization of each formulation was determined, and the results showed that the PPR5 formulation showed the longest neutralization duration, ie, 45 minutes. The neutralization durations of the PPR2, PPR3, and PPR4 formulations were 35, 25, and 38 minutes, respectively. The PPR1 formulation was unable to neutralize the acid, as shown in Figure 2C. In 2017, an interesting research article published by Dettmar et $\mathrm{al}^{5}$ described the effect of raft structure on the neutralization profile of alginate raft-forming formulations. The PPR5 formulation containing 94\% NCP showed a greater 

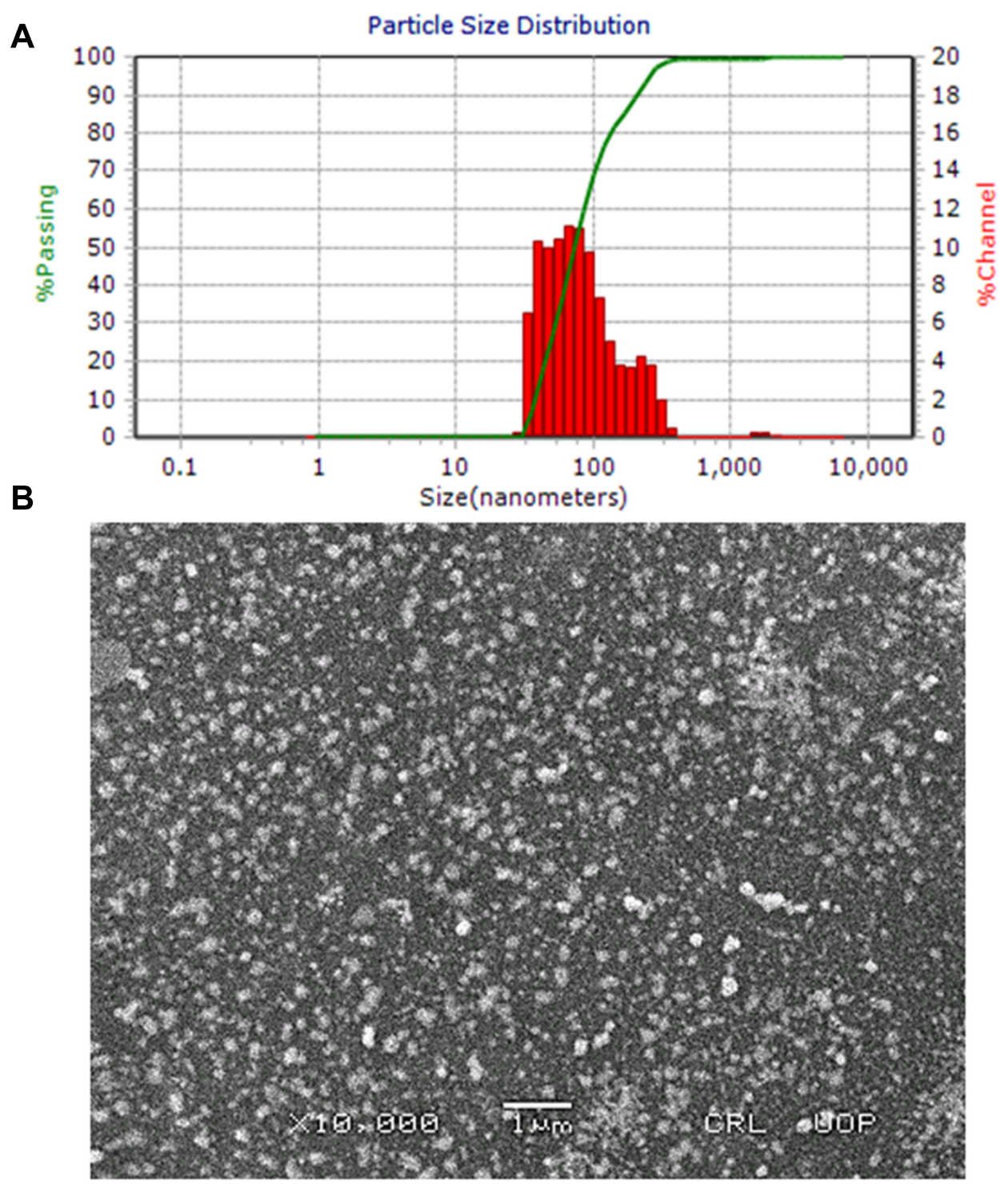

Figure I Particle size distribution of NCP prepared for the nanostructured raft (A) and SEM images showed the particle size in nano range (B).

ANC value and 45 minute duration of neutralization profile as compared to the other formulations. The high ANC and profile of neutralization profile was observed due to the greater concentration of effervescent mixture in the PPR5 formulation. The PPR4 formulation containing a lower percentage of NCP showed a lower value of ANC and moderate profile of neutralization.

\section{Swelling of NCP Raft}

The swelling behavior of the NCP raft was evaluated by a gravimetric method in SGF pH 1.2 for 60 minutes, as shown in Figure 2D. The PPR5 formulation raft showed the highest swelling (97\% after 60 minutes) in SGF compared to other formulations. This is due to the higher concentration and gelling behavior of NCP. The -OH of NCP promote wetting and swelling of the raft. The raft of the PPR3 formulation showed the least swelling $(60 \%$ after 60 minutes) compared to the other formulations. Huanbutta et $\mathrm{al}^{6}$ also studied a similar swelling percentage pattern of polymeric dosage forms. The swelling of the raft depends on the concentration of NCP in the prepared formulations. The formulation containing the maximum amount of NCP showed more swelling pattern compared to the formulations containing lower concentration of NCP. The gastric retention of the raft depends upon the swelling of the raft. If the swelling of the raft is more, the retention of the raft in the stomach is more as compared to the raft that has less capacity to swell. 

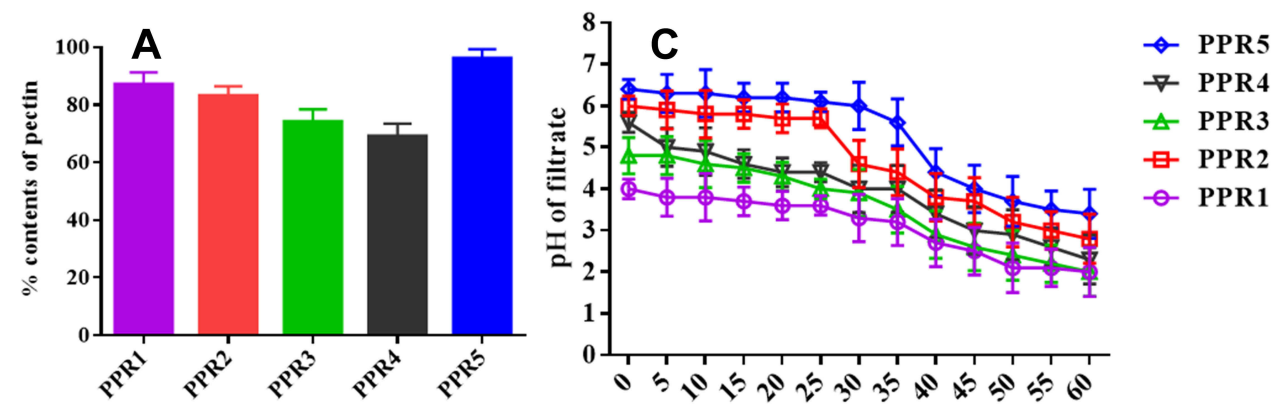

Formulations

Time (min)
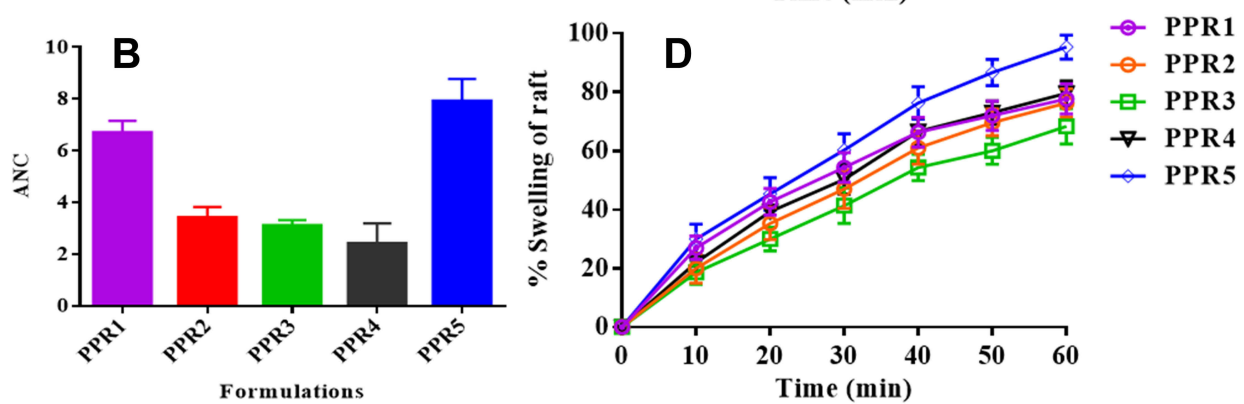

Figure 2 NCP contents (A), ANC (B), neutralization profile (C), and Swelling (D) of nanostructure NCP containing rafts.

Floating Lag Time (FLT) and Total Floating showed the minimum value of FLT. The TFT of all preTime (TFT)

The FLT of all formulations ranged from 48-61 seconds, the PPR1 formulation showed the maximum, and PPR4 forming formulations.
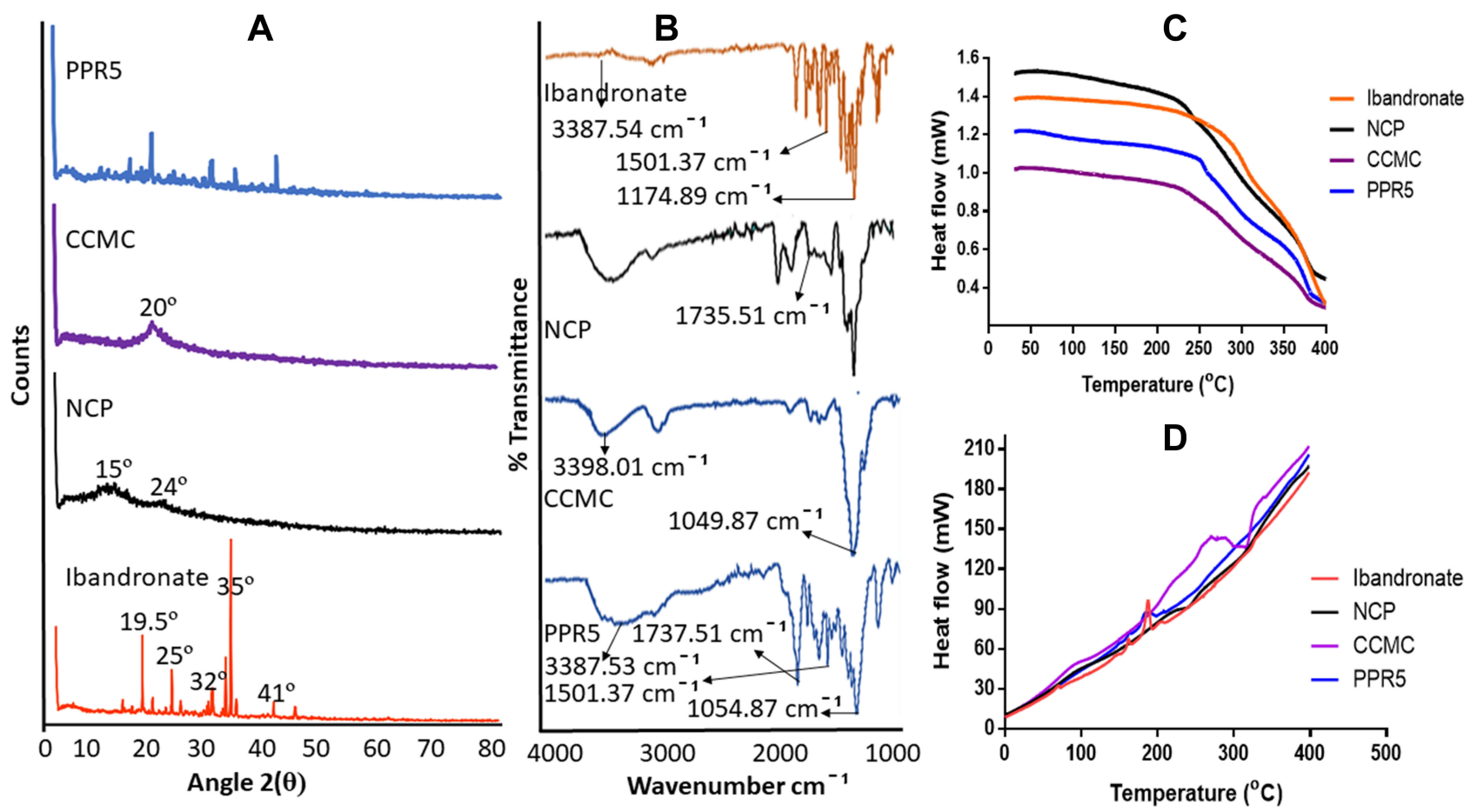

Figure 3 XRD (A), FTIR (B), TGA (C), and DSC (D) of ibandronate, NCP, CCMC, and nanostructured raft of PPR5 formulation. 


\section{Characterization}

The XRD of ibandronate, NCP, CCMC, and PPR5 formulation are shown in Figure 3A. Ibandronate showed diffraction lines $2(\theta)$ at $17^{\circ}, 19.5^{\circ}, 20.5^{\circ}, 25^{\circ}, 26^{\circ}, 32^{\circ}, 34^{\circ}, 35^{\circ}, 41^{\circ}$, and $46^{\circ}$ which indicated the crystalline nature of the drug. The diffractograms of NCP showed two diffraction peaks at $15^{\circ}$ and $24^{\circ} 2(\theta)$. The CCMC showed a line of diffraction $2(\theta)$ at $20^{\circ}$. The diffractogram of PPR5 showed many lines of diffraction, but the intensity of peaks was less as compared to the peaks of drug indicated the uniform distribution of drug. The FTIR spectra of the ibandronate, NCP, CCMC, and raft of PPR5 formulation are shown in Figure 3B. The ibandronate showed peaks at $3387.53 \mathrm{~cm}^{-1}, 1501.37 \mathrm{~cm}^{-1}$, and $1174.89 \mathrm{~cm}^{-1}$ due to $\mathrm{N}-\mathrm{H}$ group stretching, $-\mathrm{CH}$, and C-C group stretching, respectively. ${ }^{16}$ The NCP showed a welldefined peak at $1735.51 \mathrm{~cm}^{-1}$ due to the stretching of the carbonyl group $(\mathrm{C}=0)$ of ester. ${ }^{17}$ The CCMC showed two featured peaks at $1049.87 \mathrm{~cm}^{-1}$ and $3398.01 \mathrm{~cm}^{-1}$ due to vibrations of $\mathrm{C}-\mathrm{O}$ and $\mathrm{O}-\mathrm{H}$ groups, respectively. ${ }^{18}$ The raft of the PPR5 formulation showed peaks at $3387.53 \mathrm{~cm}^{-1}$, $1737.51 \mathrm{~cm}^{-1}, \quad 1501.37 \mathrm{~cm}^{-1}, 1174.89 \mathrm{~cm}^{-1}$, and $1054.87 \mathrm{~cm}^{-1}$, which correspond to the peaks of ibandronate, $\mathrm{NCP}$, and CCMC, respectively, indicating there was no chemical interaction between the drug and polymers. The TGA curves of ibandronate, NCP, CCMC, and PPR5 formulation are shown in Figure 3C. The TGA curves showed only a 5\% loss of weight of PPR5 was observed from 40 to $250^{\circ} \mathrm{C}$. ${ }^{19}$ The DSC thermograms of ibandronate, NCP, CCMC, and the raft of the PPR5 formulation are shown in Figure 3D. A thermogram of ibandronate showed exothermic peaks at $176^{\circ} \mathrm{C}$ and $191^{\circ} \mathrm{C}$ due to loss of crystalline water and $276^{\circ} \mathrm{C}$, which showed the melting point of ibandronate. ${ }^{20,21}$ The NCP and CCMC showed endothermic peaks at $250^{\circ} \mathrm{C}$ and $338^{\circ} \mathrm{C}$, respectively. The PPR5 formulation only one exothermic peaks at $191^{\circ} \mathrm{C}$ indicated the loss of crystalline water and no peak was observed at $276^{\circ} \mathrm{C}$, showing the uniform distribution and stability of the ibandronate in the formulation.

\section{Ibandronate Release from Raft}

The four different acidic media were used to check the effect of the acid strength on the raft formation and subsequently the release of ibandronate from the optimized raft forming PPR5 formulation. The PPR5 formulation subjected to dissolution for 60 minutes in $0.1 \mathrm{~N} \mathrm{HCl}, 0.5 \mathrm{~N} \mathrm{HCl}, 1 \mathrm{~N} \mathrm{HCl}$, and SGF. The PPR5 showed 99.89\%, 97.81\%, 96.34\%, and $96.16 \%$ release of ibandronate in SGF, $1 \mathrm{~N} \mathrm{HCl}, 0.5 \mathrm{~N} \mathrm{HCl}$, and $0.1 \mathrm{~N} \mathrm{HCl}$, respectively, as shown in Figure 4A. Nevertheless, the release rate of ibandronate in various mediums was equivalent, providing over $95 \%$ of ibandronate release within 20 minutes. The result indicates that ibandronate mainly existed in the aqueous solution, when the NCP raft was formed on the top layer if in contact with $0.5 \mathrm{~N} \mathrm{HCl}$ and $1.0 \mathrm{~N} \mathrm{HCl}$ solution. ${ }^{7}$ The drug was entrapped in the $\mathrm{NCP}$ raft when in contact with $0.5 \mathrm{~N} \mathrm{HCl}$ and $1.0 \mathrm{~N} \mathrm{HCl}$ solution, the ibandronate seemed to be rapidly diffused out through the foam structures of the NCP raft.
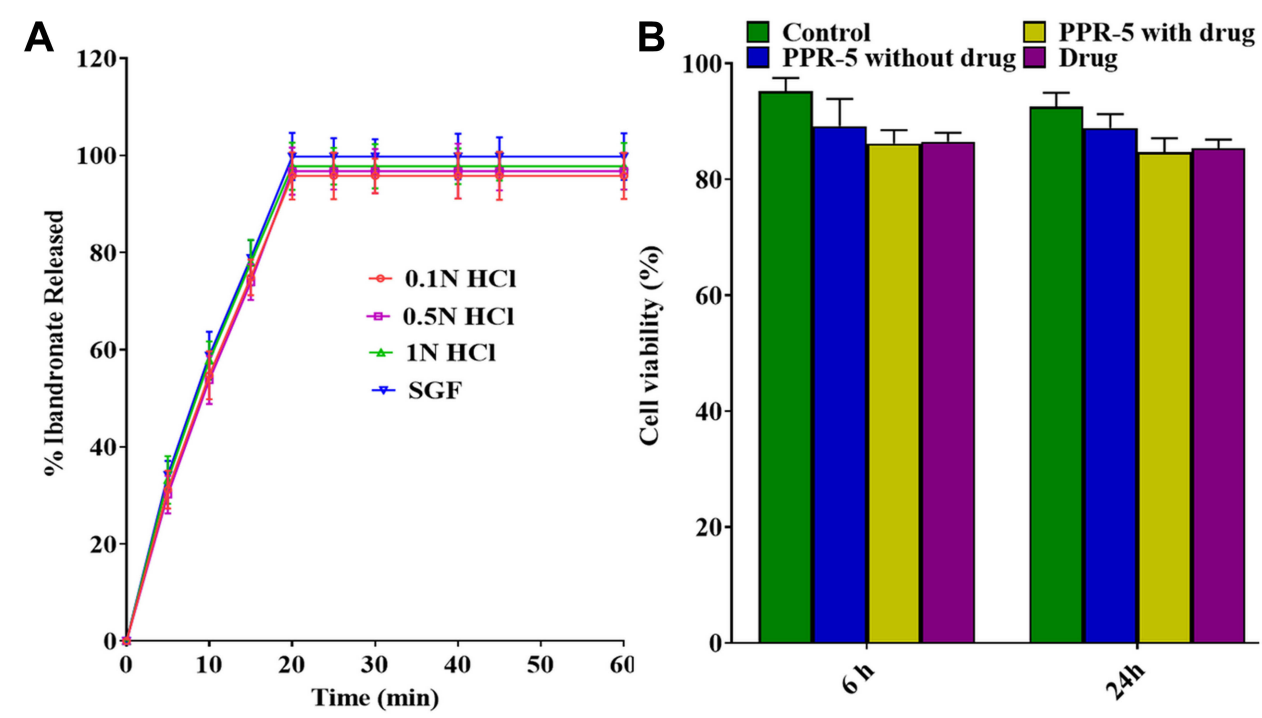

Figure 4 Release profile of ibandronate from nanostructured rafts of PPR5 in different medium $(n=6)(\mathbf{A})$ and cytotoxic study of PPR5 without and with lbandronate $(\mathbf{B})$. 


\section{Formulation (PPR5) Showed \\ Non-Cytotoxic Behavior with Caco-2 Cells}

The PPR5 showed up to $90 \%$ cell viabilities when Caco-2 cells were treated with or without drug (ibandronate) as well as with drug dispersion compared to control (medium only). ${ }^{22}$ The cells treated with PPR5-without dispersion showed a viability of $92 \%$ and $89 \%$ after 6 hours and 24 hours, respectively ( $P=0.123)$, as shown in Figure 4B. The toxicity profile of PPR5 formulation based on NCP polymer for raft seems to be very close to control, suggesting a safe formulation. Our study is compatible to that of Severino et al, ${ }^{23}$ who observed the non-cytotoxic behavior of nanoparticle using Caco-2 and HEPG-2 cell lines.

\section{Stability Studies}

At 0 -month period the hardness and disintegration time of PPR5 formulation were $4.9 \pm 1.09 \mathrm{~kg} / \mathrm{cm}^{2}$ and $49 \pm 2.45 \mathrm{sec}-$ onds, respectively. The FLT and TFT were $51 \pm 2.34$ seconds and 5.2 \pm 3.12 hours, respectively, as shown in Table 3 . The percentage release of drug and assay showed $99.87 \pm 3.09 \%$ and $98.54 \pm 1.89 \%$ ibandronate, respectively. Goh et $\mathrm{al}^{24}$ observed the similar findings of stability studies of pharmaceuticals containing raft forming polymer. At 1 month, the hardness and disintegration time of tablets were $4.8 \pm 1.34 \mathrm{~kg}$ / $\mathrm{cm}^{2}$ and $47 \pm 3.09$ seconds, respectively. The FLT and TFT of the raft were $48 \pm 3.56$ seconds and 5.0 \pm 2.67 hours, respectively. The percentage release of drug and assay showed $96.38 \pm 3.01 \%$ and $94.38 \pm 2.78 \%$ ibandronate, respectively. At the 3rd month, the hardness and disintegration time of tablets were $4.5 \pm 1.30 \mathrm{~kg} / \mathrm{cm}^{2}$ and $43 \pm 1.45$, respectively. The FLT and TFT of the raft were $45 \pm 1.90$ seconds and $4.6 \pm 2.87$ hours, respectively, as shown in Table 3 . The percentage release of drug and assay showed $92.56 \pm 2.98 \%$ and 91.29 $\pm 3.08 \%$ ibandronate, respectively. At the 6 th month, the hardness and disintegration time tablets were $4.3 \pm 0.23$ $\mathrm{kg} / \mathrm{cm}^{2}$ and $41 \pm 2.56$ seconds, respectively. The FLT and TFT of the raft were $44 \pm 1.51$ seconds and $4.4 \pm 2.90$ hours,

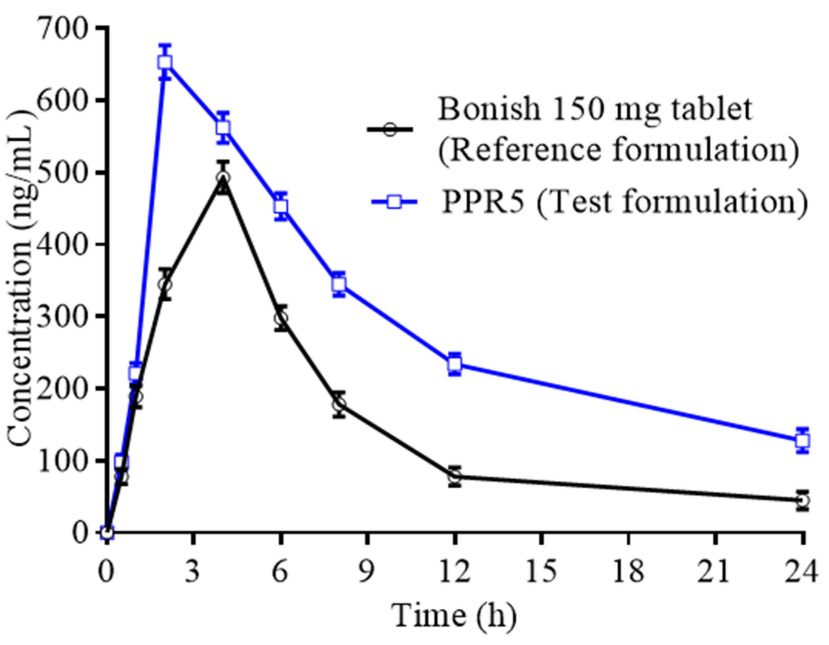

Figure 5 Mean ibandronate profile after oral administration of test and reference formulation $(n=6)$.

respectively. The percentage release of drug and assay showed $89.67 \pm 3.01 \%$ and $89.16 \pm 2.45 \%$ ibandronate, respectively.

\section{Pharmacokinetic Analysis}

To investigate the in vivo behavior of the raft forming ibandronate tablets, the mean plasma concentration-time profiles of ibandronate following oral administration of Bonish tablets (reference formulation) and PPR5 tablet (test formulation) in rats were estimated (Figure 5). Various pharmacokinetic parameters such as $\mathrm{C}_{\max }(\mathrm{ng} / \mathrm{mL})$, $\mathrm{t}_{\max }$ (h), $\mathrm{AUC}_{0-\mathrm{t}}$ (ng/mL.h), $\mathrm{AUC}_{0-\infty}$ (ng/mL.h), AUMC (ng/mL.h), $\mathrm{t}_{1 / 2}\left(\mathrm{~h}^{-1}\right)$, MRT (h), and kel $\left(\mathrm{h}^{-1}\right)$ were calculated by non-compartmental approach and presented in Table 4. The difference between the pharmacokinetic parameters was statistically analysed by applying Student's $t$-test (Table 4) at $5 \%$ level of significance. From the results, it was observed that the $t_{\max }$ for the test formulation was $2 \pm 0.025$ hours $(P=0.0001)$ and that the $t_{\max }$ of the reference was $4 \pm 1.398$ hours $(P=0.0004)$. The peak plasma concentration of the PPR5 test and the reference formulation was $653 \pm 0.097$ $\mathrm{ng} / \mathrm{mL}$ and $493 \pm 0.237 \mathrm{ng} / \mathrm{mL}$, respectively. The $t_{1 / 2}$ of the

Table 3 Results of Stability Studies

\begin{tabular}{|c|c|c|c|c|c|c|}
\hline $\begin{array}{l}\text { Duration in } \\
\text { Months }\end{array}$ & $\begin{array}{l}\text { Hardness } \\
\left(\mathrm{kg} / \mathrm{cm}^{2}\right)\end{array}$ & $\begin{array}{l}\text { Disintegration Time } \\
\text { (seconds) }\end{array}$ & $\begin{array}{l}\text { FLT } \\
\text { (seconds) }\end{array}$ & $\begin{array}{l}\text { TFT } \\
\text { (hours) }\end{array}$ & $\begin{array}{l}\% \text { Release of } \\
\text { Drug }\end{array}$ & Assay (\%) \\
\hline 0 & $4.9 \pm 1.09$ & $49 \pm 2.45$ & $5 I \pm 2.34$ & $5.2 \pm 3.12$ & $99.87 \pm 3.09$ & $98.54 \pm 1.89$ \\
\hline I & $4.8 \pm 1.34$ & $47 \pm 3.09$ & $48 \pm 3.56$ & $5.0 \pm 2.67$ & $96.38 \pm 3.01$ & $94.38 \pm 2.78$ \\
\hline 3 & $4.5 \pm 1.30$ & $43 \pm 1.45$ & $45 \pm 1.90$ & $4.6 \pm 2.87$ & $92.56 \pm 2.98$ & $91.29 \pm 3.08$ \\
\hline 6 & $4.3 \pm 0.23$ & $4 I \pm 2.56$ & $44 \pm|.5|$ & $4.4 \pm 2.90$ & $89.67 \pm 3.01$ & $89.16 \pm 2.45$ \\
\hline
\end{tabular}


Table 4 Pharmacokinetic Parameters of lbandronate from PPR5 and Bonish $150 \mathrm{mg}$ Tablets $(\mathrm{n}=6)$

\begin{tabular}{|l|l|l|l|}
\hline Parameters & $\begin{array}{l}\text { Test } \\
\text { Formulation } \\
\text { (PPR5) }\end{array}$ & $\begin{array}{l}\text { Reference } \\
\text { Formulation } \\
\text { (Bonish I50 mg } \\
\text { Tablets) }\end{array}$ & P-value \\
& & $4 \pm 1.398$ & 0.0001 \\
\hline$t_{\max }(\mathrm{h})$ & $2 \pm 0.025$ & $493 \pm 0.237$ & 0.0002 \\
$C_{\max }(\mathrm{ng} / \mathrm{mL})$ & $653 \pm 0.097$ & $6.139 \pm 1.142$ & 0.0001 \\
$t_{1 / 2}(\mathrm{~h})$ & $11.69 \pm 2.025$ & $3708.25 \pm 3.418$ & 0.0001 \\
AUC $_{(0-\mathrm{t})}(\mathrm{ng} / \mathrm{mL} . \mathrm{h})$ & $6899.25 \pm 3.467$ & $4106.81 \pm 4.104$ & 0.0004 \\
AUC $_{(0-\infty)}(\mathrm{ng} / \mathrm{mL} . \mathrm{h})$ & $9058.83 \pm 5.612$ & $40,051.83 \pm 3.412$ & 0.0001 \\
AUMC $(\mathrm{ng} / \mathrm{mL} . \mathrm{h})$ & $149,523.18 \pm 3.676$ & $9.75 \pm 0.379$ & 0.0003 \\
MRT $(\mathrm{h})$ & $16.50 \pm 1.296$ & & \\
\hline
\end{tabular}

test and reference formulation was $11.69 \pm 2.025$ hours and $6.139 \pm 1.142$ hours, respectively. The observed $\mathrm{AUC}_{(0-\mathrm{t})}$ of the PPR5 test formulation was $6899.25 \pm 3.467 \mathrm{ng} / \mathrm{mL} . \mathrm{h}$, which was higher than the $\mathrm{AUC}_{(0-\mathrm{t})}$ of the reference formulation, ie, $3708.25 \pm 3.418 \mathrm{ng} / \mathrm{mL} . \mathrm{h}$, indicating the bioavailability $^{25}$ of the PPR5 was higher than that of the reference formulation. The $\mathrm{AUC}_{(0-\infty)}$ values of test and reference formulation were $9058.83 \pm 5.612 \mathrm{ng} / \mathrm{mL} . \mathrm{h}$ and $4106.81 \pm 4.104 \mathrm{ng} / \mathrm{mL} . \mathrm{h}$, respectively. An increase in AUC, an important tool for the estimation of bioavailability, could be correlated to the increase in bioavailability of drug. The use of NCP in the formulation showed the highly porous and absorbent nature of the raft. ${ }^{26}$ The MRT of the test and reference formulation was $16.50 \pm 1.296$ hours and 9.75 \pm 0.379 hours, respectively, as mentioned in Table 4 . The use of NCP enhances the release of ibandronate form PPR5 and PEG 400 improves the penetration of ibandronate through the stomach. The test formulation (PPR5) showed greater bioavailability compared to the reference formulation.

\section{Conclusion}

The NCP was successfully prepared from citrus pectin and showed effective and porous raft formation. These newly prepared tablets rapidly dispersed in the SGF, rapidly released the ibandronate, and more than 90\% drug was release within 20 minutes. This dosage form effectively neutralizes the acidity of the stomach and maintains the $\mathrm{pH}$ of the stomach above 3.5 to prevent the reflux of ibandronate into the esophagus. The bioavailability of newly developed PPR5 was greater than the already marketed formulation. This novel NCP raft forming formulation can be the best alternative for the delivery of ibandronate through the oral route.

\section{Acknowledgment}

The authors are thankful to Global Pharmaceuticals for providing the Ibandronate.

\section{Disclosure}

The authors report no conflicts of interest in this work.

\section{References}

1. Lin J. Bisphosphonates: a review of their pharmacokinetic properties. Bone. 1996;18(2):75-85. doi:10.1016/8756-3282(95)00445-9

2. Sriamornsak P. Application of pectin in oral drug delivery. Expert Opin Drug Deliv. 2011;8(8):1009-1023. doi:10.1517/17425247.2011.584867

3. Jiang C-M, Wu M-C, Chang W-H, Chang H-M. Change in particle size of pectin reacted with pectinesterase isozymes from pea (Pisum sativum L.) sprout. J Agric Food Chem. 2001;49:4383-4387. doi:10. 1021/jf0100671

4. Abbas G, Hanif M. pH-sensitive pectin polymeric rafts for controlled-release delivery of pantoprazole sodium sesquihydrate. J Appl Polym Sci. 2017;134. doi:10.1002/app.44442

5. Dettmar PW, Gil-Gonzalez D, Fisher J, et al. A comparative study on the raft chemical properties of various alginate antacid raft-forming products. Drug Dev Ind Pharm. 2017;44:30-39. doi:10.1080/ 03639045.2017.1371737

6. Huanbutta K, Cheewatanakornkool K, Terada K, Nunthanid J, Sriamornsak P. Impact of salt form and molecular weight of chitosan on swelling and drug release from chitosan matrix tablets. Carbohydr Polym. 2013;97(1):26-33. doi:10.1016/j.carbpol.2013.04.073

7. Jang SW, Lee JW, Ryu DS, Son M, Kang MJ. Design of $\mathrm{pH}$-responsive alginate raft formulation of risedronate for reduced esophageal irritation. Int J Biol Macromol. 2014;70:174-178. doi:10.1016/j.ijbiomac.2014.06.048

8. Nazzal S, Khan MA. Controlled release of a self-emulsifying formulation from a tablet dosage form: stability assessment and optimization of some processing parameters. Int J Pharm. 2006;315 (1-2):110-121. doi:10.1016/j.ijpharm.2006.02.019

9. Hanif M, Abbas G. pH-responsive alginate-pectin polymeric rafts and their characterization. Adv Polym Technol. 2018;37(5):1496-1506.

10. Abbas G, Hanif M, Khan MA. pH responsive alginate polymeric rafts for controlled drug release by using box behnken response surface design. Des Monomers Polym. 2017;20(1):1-9. doi:10.1080/15685 551.2016.1231046

11. Prajapati ST, Mehta AP, Modhia IP, Patel CN. Formulation and optimisation of raft-forming chewable tablets containing $\mathrm{H} 2$ antagonist. Int J Pharm Investig. 2012;2(4):176. doi:10.4103/2230-973X.106988

12. Akseli I, Abebe A, Sprockel O, Cuitiño AM. Mechanistic characterization of bilayer tablet formulations. Powder Technol. 2013;236:30-36. doi:10.1016/j.powtec.2012.05.048

13. Jonassen H, Treves A, Kjøniksen A-L, Smistad G, Hiorth M. Preparation of ionically cross-linked pectin nanoparticles in the presence of chlorides of divalent and monovalent cations. Biomacromolecules. 2013;14(10):3523-3531. doi:10.1021/bm4008474

14. Zaman M, Qureshi S, Sultana K, et al. Application of quasi-emulsification and modified double emulsification techniques for formulation of tacrolimus microsponges. Int $J$ Nanomedicine. 2018;13:4537. doi:10.2147/IJN.S166413

15. Awad H, Aboul-Enein HY. A validated HPLC assay method for the determination of sodium alginate in pharmaceutical formulations. J Chromatogr Sci. 2012;51:208-214. doi:10.1093/chromsci/bms129

16. Reddy GM, Bhaskar BV, Reddy PP, et al. Structural identification and characterization of potential impurities of pantoprazole sodium. $J$ Pharm Biomed Anal. 2007;45(2):201-210. doi:10.1016/j.jpba. 2007.05.032 
17. Kyomugasho C, Christiaens S, Shpigelman A, Van Loey AM, Hendrickx ME. FT-IR spectroscopy, a reliable method for routine analysis of the degree of methylesterification of pectin in different fruit-and vegetable-based matrices. Food Chem. 2015;176:82-90. doi:10.1016/j.foodchem.2014.12.033

18. Ding C, Zhang M, Li G. Preparation and characterization of collagen/ hydroxypropyl methylcellulose (HPMC) blend film. Carbohydr Polym. 2015;119:194-201. doi:10.1016/j.carbpol.2014.11.057

19. Malpezzi L, Maccaroni E, Carcano G, Ventimiglia G. Structural and thermal characterization of sodium ibandronate monohydrate. $J$ Therm Anal Calorim. 2012;109(1):373-379. doi:10.1007/s10973-011-1698-Z

20. Zupančič V, Ograjšek N, Kotar-Jordan B, Vrečer F. Physical characterization of pantoprazole sodium hydrates. Int J Pharm. 2005;291 (1-2):59-68. doi:10.1016/j.ijpharm.2004.07.043

21. Nagarsenker M, Garad S, Ramprakash G. Design, optimization and evaluation of domperidone coevaporates. Journal of Control Release. 2000;63(1-2):31-39. doi:10.1016/S0168-3659(99)00177-7

22. Khorrami S, Zarrabi A, Khaleghi M, Danaei M, Mozafari M. Selective cytotoxicity of green synthesized silver nanoparticles against the MCF-7 tumor cell line and their enhanced antioxidant and antimicrobial properties. Int J Nanomedicine. 2018;13:8013. doi:10.2147/IJN.S189295
23. Severino P, Andreani T, Jäger A, et al. Solid lipid nanoparticles for hydrophilic biotech drugs: optimization and cell viability studies (Caco-2 \& HEPG-2 cell lines). Eur J Med Chem. 2014;81:28-34. doi:10.1016/j.ejmech.2014.04.084

24. Goh CH, Heng PWS, Chan LW. Alginates as a useful natural polymer for microencapsulation and therapeutic applications. Carbohydr Polym. 2012;88:1-12. doi:10.1016/j.carbpol.2011.11.012

25. Liu H, Du K, Li D, et al. A high bioavailability and sustained-release nano-delivery system for nintedanib based on electrospray technology. Int J Nanomedicine. 2018;13:8379. doi:10.2147/IJN. S181002

26. Abbas G, Hanif M. Development and pharmacokinetic evaluation of alginate-pectin polymeric rafts forming tablets using box behnken design. Drug Dev Ind Pharm. 2018;44(12):2026-2037. doi:10.1080/ 03639045.2018.1508221
International Journal of Nanomedicine

\section{Publish your work in this journal}

The International Journal of Nanomedicine is an international, peerreviewed journal focusing on the application of nanotechnology in diagnostics, therapeutics, and drug delivery systems throughout the biomedical field. This journal is indexed on PubMed Central, MedLine, CAS, SciSearch ${ }^{\circledR}$, Current Contents ${ }^{\mathbb{B}} /$ Clinical Medicine,

\section{Dovepress}

Journal Citation Reports/Science Edition, EMBase, Scopus and the Elsevier Bibliographic databases. The manuscript management system is completely online and includes a very quick and fair peer-review system, which is all easy to use. Visit http://www.dovepress.com/ testimonials.php to read real quotes from published authors. 